\title{
ANTES DE SAIR: A MEMÓRIA DAS COISAS
}

BEFORE YOU LEAVE: THE MEMORY OF THINGS

\section{Flávia Sangiorgi Dalla Bernardina}

PPGA-UFES

Resumo: Trata-se da análise crítica da exposição Antes de Sair, do artista Luiz Ernesto, realizada no Paço Imperial (RJ) em março de 2017, com organização e curadoria do próprio. O artista expõe fotografias do apartamento da família em vias de esvaziamento, acompa-nhadas de textos poéticos, devidamente emoldurados, que acompanham as imagens e enigmatizam seus sentidos, permitindo áreas de manobra para a invenção. Pontua-se, na análise da exposição, sobre a questão da transmissão e como a mesma se opera através das palavras e das imagens na contemporaneidade.

Palavras-chave: memória, transmissão, imagem, palavra.

Abstract: This is the critical analysis of the exhibition Before the Exit, by the artist Luiz Ernesto, held in Paço Imperial (RJ) in March 2017, with the organization and curation of his own. The artist exposes photographs of the family apartment in the process of emptying them, accompa-nied by poetic texts, duly framed, that accompany the images and enigmatize their senses, allowing areas of maneuver for the invention. In the analysis of the exposition, the question of transmission is analyzed and how it operates through words and images in contemporary times.

Keywords: memory, transmission, image, word.. 


\section{Prelúdio}

As coisas, acostumadas aos seus donos, haviam esperado em vão pelo seu retorno. Os quadros escurecidos pela poeira, os abajures com as cúpulas amareladas, as fruteiras de prata enegrecidas, as toalhas de linho com seus bordados redesenhados pelas traças desapareciam pouco a pouco à medida que folhas de jornal velho as embrulhavam. Eram agora fragmentos desmantelados, de uma história que terminava e na qual se vivera a ilusão de perenidade. A serenidade melancólica do apartamento augurava o seu futuro: seria esvaziado e vendido. (LUIZ ERNESTO, 2017)

Trata-se do prelúdio da exposição "Antes de sair", do artista Luiz Ernesto, que ocupou a sala "Academia dos Seletos", no Paço Imperial (RJ) em março de 2017. Com organização do próprio artista, o mesmo afirma que não houve curadoria. Entretanto, está nítido que a curadoria foi realizada pelo próprio artista, considerando que a disposição das imagens e textos no espaço expositivo compõem a obra.

Aproprio-me, e, portanto, aumento um ponto ao título da exposição - Antes de sair: a memória das coisas. Hoje, nesse depois que é agora, vejo que o título ainda está incompleto, assim como, ao contar ou recontar uma história, sempre inventamos algo em torno do que falta. Talvez meIhor seria, "Antes de sair: a memória das coisas esquecidas."

As fotografias expostas são do apartamento da família do artista, que estava - à época do registro - em vias de esvaziamento, e onde o mesmo realiza uma espécie de inventário dos objetos que ali habitaram. De início, a ideia era registrar as imagens do local para arquivo pessoal. Todavia, as coisas, na medida em que eram retiradas de seus lugares habituais passaram a evocar histórias desconhecidas ou inventadas.

As imagens não mostram muito do apartamento - o pé de um piano de cauda, o corredor, uma cadeira na cozinha, a antessala, o lustre. 0
Vista da exposição Antes de Sair, artista Luiz Ernesto - sala "Academia dos Seletos", Paço Imperial, Rio de Janeiro, 2017.

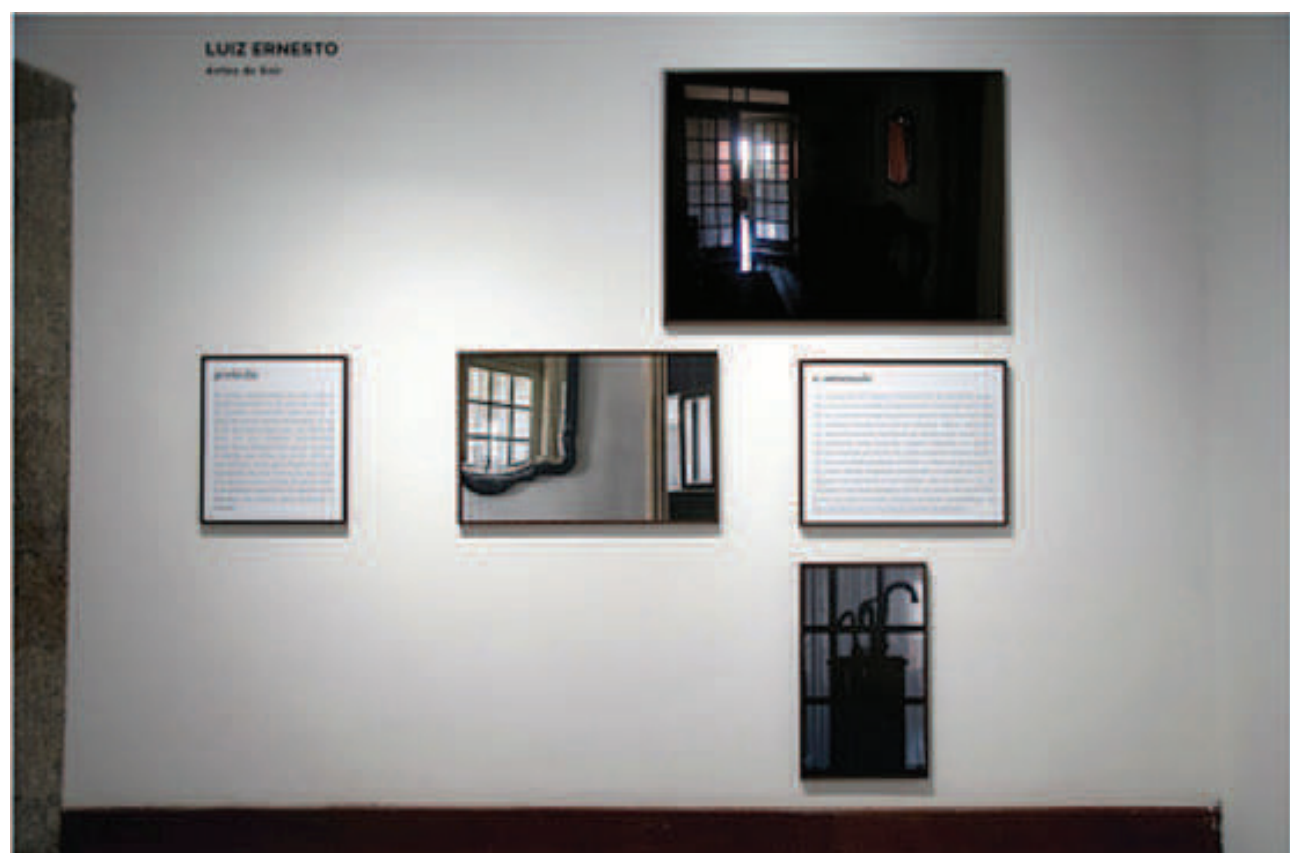




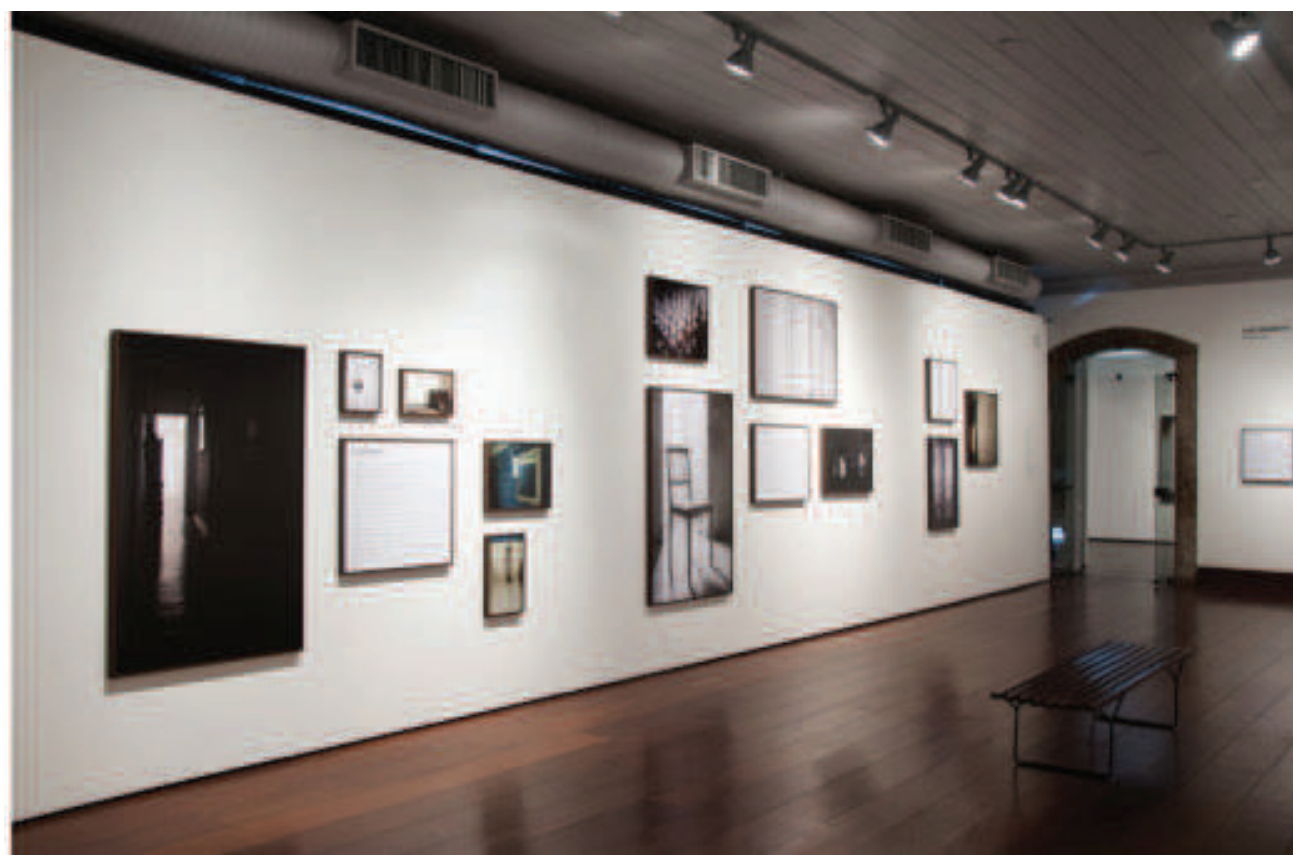

Vista da exposição Antes de Sair, artista Luiz Ernesto, sala "Academia dos Seletos", Paço Imperial, Rio de Janeiro, 2017

texto, de autoria do próprio artista, é apresentado em molduras antigas, assim como as fotografias, e faz o papel de criar novas imagens, aquelas que não estão dadas a ver.

Pela maneira como estão expostos, o artista assume que valoriza os intervalos e os espaços entre uma imagem e outra, entre um texto e uma imagem, para que nessa respiração, a montagem apresente graus de visibilidade que opere alguma imaginação do espectador.

Antes de sair é antes de mais nada o registro de uma lembrança falha, que vem aos pedaços, um ato de invenção. Na fala do próprio artista, "mais do que falar de um lugar e de objetos, ela fala da finitude, da perda, e em última instância da morte."'

O passado e os respectivos usos que damos a ele dizem respeito aos modos de encarar a finitude e desde o ano 2000, o artista desenvolve trabaIhos que relacionam a imagem às palavras.

1 Entrevista concedida pelo artista Luiz Ernesto ao Canal Arte (www.canal-arte.com), publicado em 07 de abril de 2017.
Da antessala à cozinha, passando pelas coisas pequenas e as coisas no limbo, o artista reconta essa história a partir das insignificâncias, do que não é visto, da desimportância dos espaços de passagem, das coisas acostumadas.

Quando o artista se vale da palavra para materializar uma espécie de testemunho - ou testamento - do que deixará de existir, ele evidencia que as imagens por si só não bastam para operar a transmissão. É necessário fazer o uso da palavra. Mas não é de qualquer palavra que estamos falando...

Estas avançam não para cercar os objetos, congelando-os para um fim específico, mas para, através da poesia, ganhar outros usos e sentidos. Uma operação que parte do meio do caminho, e coloca a língua a serviço da recriação da realidade e não da sua mera descrição.

Um exemplo é quando o artista fala da compoteira:

Algumas coisas convivem conosco por tanto tempo que se tornam invisíveis. Foi assim com a compoteira de opalina. De um azul-cobalto intenso, 
Vista da exposição Antes de Sair, artista Luiz Ernesto - sala

"Academia dos Seletos", Paço Imperial, Rio de Janeiro, 2017.

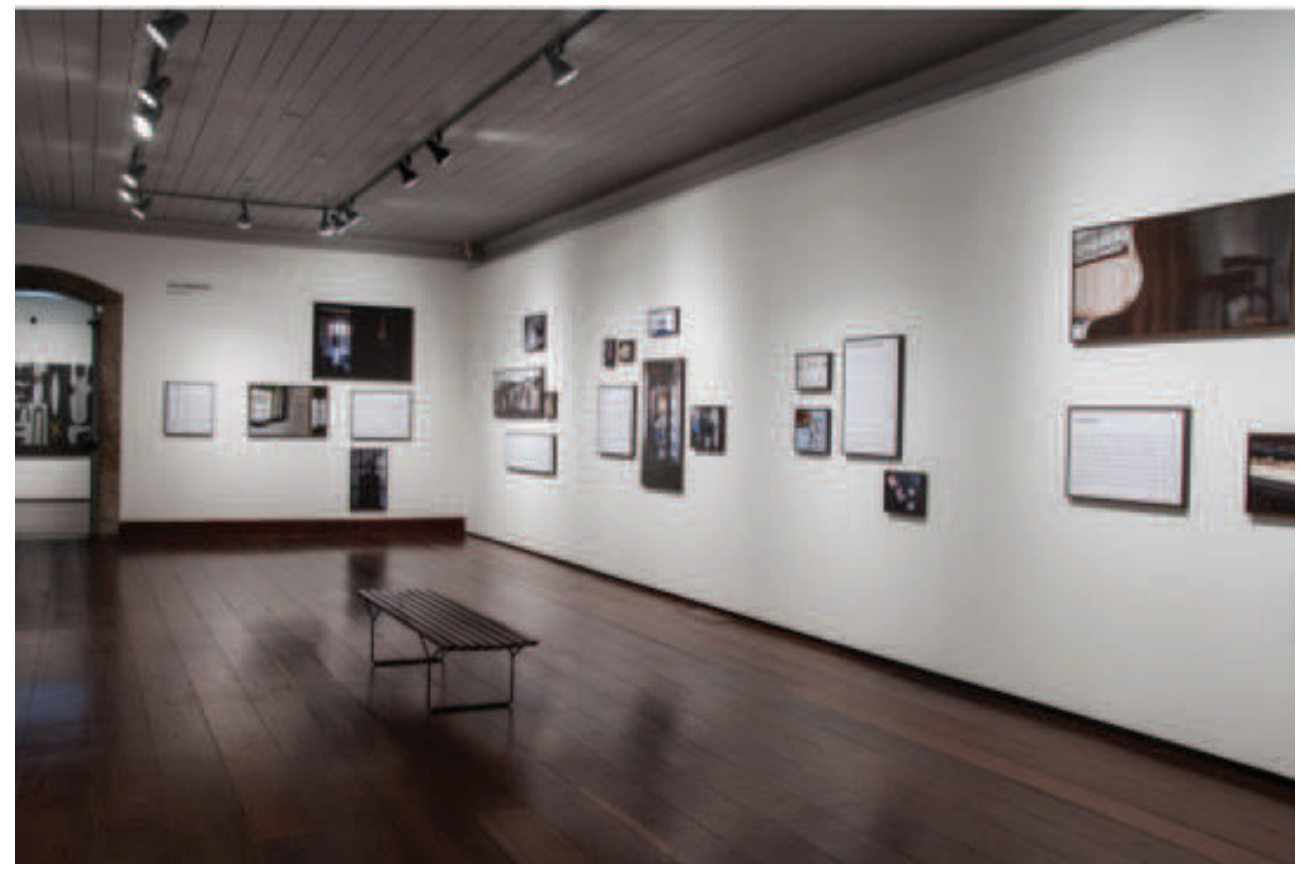

era circundada por ornamentos de prata. Durante anos, repousou sobre a pequena mesa em semicírculo do menor cômodo do apartamento. Ali, sem que the fosse dada qualquer importância, servia para guardar recibos de contas e outras quinquilharias. Um acontecimento fortuito a resgatou de sua existência rarefeita: um antiquário, em uma visita atestara o seu valor. Migrou então para a vitrine da sala do piano junto com os objetos importantes da casa. Sua notoriedade repentina reavivou detalhes inusitados e enigmáticos velados até então pelo hábito: um cervo em prata, com chifres pontiagudos, encimava sua tampa arredondada servindo-lhe de alça. No topo de sua colina azul, o animal não parecia se orgulhar de sua posição. Melancólico e desconfiado olhava para trás, como alguém que busca na distância turva fragmentos espalhados de seu próprio passado. ${ }^{2}$

2 Texto retirado da obra "A compoteira", exposição Antes de Sair, artista Luiz Ernesto, Paço Imperial, abril de 2017.

\section{O Corredor}

Francisco Régis Lopes no texto Cultura Material e escrita da história: a imposição da palavra na exposição do objeto (2010), aponta que na área dos usos da memória, a relação entre a velocidade e o prazer das relações de consumo indicam que vivemos novas maneiras de usar o passado, vide as enxurradas de biografias e autobiografias nas gôndolas das livrarias.

No processo de musealização a palavra cerca o objeto, atribuindo-lhe uma existência específica, para atender a certas demandas. Isso evidencia o que Walter Benjamin trata como o fracasso da experiência e a perda da capacidade de narrar. Se pensarmos que em uma sociedade com memória coletiva comum, compartilhada, não haveria necessidade de peças identificadas, que nomeiem aquilo que já é conhecido.

Se por um lado, na história, temos a impossibilidade de dizer - em virtude da magnitude de certos traumas, por outro lado nos degladiamos com o excesso de lembrança. 


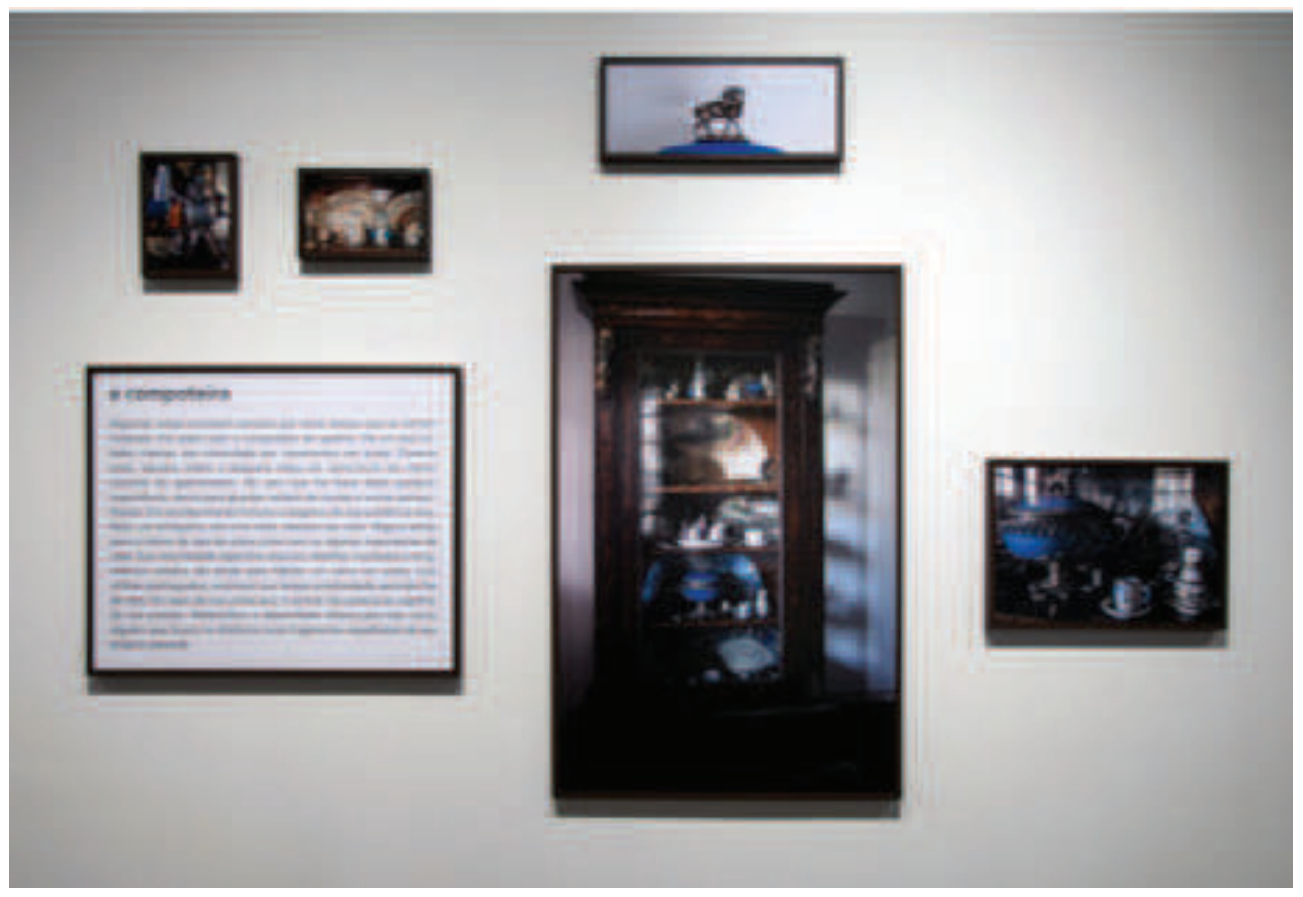

Imagem da obra "A compoteira”, Exposição Antes de Sair, artista Luiz Ernesto, Paço Imperial, Rio de Janeiro, 2017.

Algumas questões me ocorrem: uma delas - e talvez a primordial para justificar a escolha do tema, é o motivo pelo qual as memórias desse outro, de objetos que nunca fizeram parte do meu cotidiano, me conectam a ele, e me convocam de tal maneira que me sinto impossibilitada de sair do espaço expositivo.

Aponto algumas reflexões que partem da exposição do artista Luiz Ernesto, mas que avançam na obra de Walter Benjamin (2011) e circundam a possível diferenciação - talvez por mim inventada - entre rastro e vestígio, sobretudo com relação à escrita como fundação de memória.

No caso da memória apresentada pelo artista, o vazio que os objetos deixam em sua petrificação resta, nas fotografias, por demais reforçado. No caso, a palavra não excede, mas desprograma, desinforma, amolece e dá vida. Quando um outro uso é vislumbrado - os objetos elevados à condição de narradores transfor- mam aquilo que poderia ser excesso, em resto.

As questões sobre vestígio e rastro avançarei mais adiante, sobretudo a partir do relato de Benjamin no texto Experiência e Pobreza (2011) sobre o quarto burguês dos anos 1880, como um lugar onde não há nada a fazer ali, tamanho o excesso de descrições, objetos e adjetivos, uma espécie de aconchego construído.

Antes disso, e remetendo às questões da experiência em Benjamin - na tentativa de descolar algumas camadas dos enigmas que oferece em seus textos - se de fato, perdemos a capacidade de narrar, perdemos igualmente a capacidade de transmitir? Como se opera a transmissão na contemporaneidade?

Benjamin, quando fala do fim da experiência, enfrenta alguns pontos cruciais: a continuidade entre as gerações, a palavra compartilhada numa tradição comum e a questão das viagens como fonte de experiência autêntica, embora reconheça sua impossibilidade na nossa (pós) 
modernidade, como se estivéssemos incapacitados de compartilhar o comum. Carentes de rastros, carentes de experiência.

Será que esta - a experiência - tal como vivenciamos hoje, de fato opera a transmissão, no sentido de criar pontos em comum, laços, aqueles necessários para vincular escrevente e leitor, artista e espectador, interlocutor e ouvinte?

Em se tratando da escrita como lugar de memória, ao que parece, esta deixa muito menos espaços vazios - por assim dizer, rastros - que a oralidade, justamente pela possibilidade de transcrever a realidade e assim encurtar o vão entre a aparência e a realidade.

Aqui, uma via em direção ao texto de Vilém Flusser, Pretextos para Poesia (1985), onde trata de dois eventos que considera cruciais para a história da escrita alfabética: (i) o primeiro, na metade do segundo milênio A.C, que foi a mecanização da escrita através da criação das letras, do alfabeto, o que liberou o escrevente da barreira da imagem, e abriu caminho para o discurso linear codificado: "escrever passou a ser alinhar letras, para com elas formar palavras, com estas sentenças, e com estas discursos" (FLUSSER, 1985); (ii) o segundo, com a criação da imprensa, e o fato de as letras serem manipuláveis e multiplicáveis mecanicamente, o que emancipou o escrevente da barreira material e abriu caminho rumo à informação pura.

Escrever deixa de ser desenhar letras para manipular máquinas, sendo que o valor do que é escrito não está mais na coisa em si, mas na informação que ela carrega. A escrita à serviço da informação, adequada, formatada, para a democratização do alfabeto, para a generalização do pensamento linear discursivo. Excesso de vestígios e falta de rastros.

Isso sem mencionar a relação do corpo com o ato de escrever, a modificação do embate do corpo com a letra, o enfrentamento com a pena, que implica numa diferença de velocidade e por conseguinte, de perdas, frente às formas de escrever atuais - sem mencionar os ideogramas chineses, que passam ao largo de uma codificação, mas exprimem um conceito, uma ação.

Retomo a rota com Benjamin, em O Narrador (2011), quando, bem antes de Flusser elabora tais digressões e aponta a morte da narrativa pelo surgimento dos romances.

Ora, se pensarmos que os romances se vinculam à criação da imprensa e ao suporte livro, faz sentido tal afirmativa. Com a imprensa, tem início o declínio da tradição oral, da experiência passada de pessoa para pessoa, da possibilidade de se deixar rastros para surgimento de uma palavra em comum. O comum que se opera na perda e não na transcrição fidedigna do que foi recebido pelo narrador.

Quando passamos à reprodução mecânica da escrita, codificamos excessivamente e adequamos a escrita ao meio em que será veiculada hoje isso sendo levado às últimas consequências, vide os limites de caracteres em espaços para publicação, os 140 caracteres do twitter, as limitações da escrita nas redes sociais - colocando-a à serviço da informação. Perdemos, na medida em que avançamos, a capacidade de deixar rastros, essenciais para que a transmissão se opere.

Jean Marie Gagnebin ${ }^{3}$ em o O rastro e a cicatriz: metáforas da memória (2014) aponta que escrita e rastro por certo tempo foram utilizadas como sinônimos. A escrita por muito tempo foi considerada o traço mais duradouro, que sobrevive inclusive à morte do autor. Não por acaso, a palavra sema significa originariamente "túmulo" para depois, significar "signo". Como pontua Gagnebin, "túmulo, signo, palavra, escrita, todos lutam contra o esquecimento" (GAGNEBIN, 2014, pg, 112).

3 GAGNEBIN, Jean Marie. Lembrar, escrever, esquecer. "O rastro e a cicatriz: metáfora da memória." 2a ed. São Paulo: Editora 34, 2009. 
Nesse ponto surge o que Benjamin denomina, como "casa de vidro" e "espaços de pelúcia". Tais ambiências descritas pelo autor em Experiência e Pobreza (2011), tratam do apagamento, da frieza (no caso do vidro) e do excesso, da artificialidade (no caso da pelúcia). O primeiro, materializado na arquitetura moderna de Adolf Loos e Le Corbusier, tendo o vidro como suporte, material frio e duro, no qual nada se fixa, nem adere; lugares difíceis de deixar rastros. Já os espaços de pelúcia, caracterizados pelo excesso de bibelôs, trata-se do lugar onde não se tem nada a fazer, nos dizeres de Benjamin, " pois não há nesse espaço um único ponto em que seu habitante não tivesse deixado seus vestígios (BENJAMIN, 2011) - e é desse trecho que traço a possível diferenciação, ainda que sutil, entre rastro e vestígio. Um espaço altamente adequado ao que está dentro, mas não ao seu interior.

Vestígio assume aqui o caráter daquilo que foi criado, programado para adequar-se ao meio, e por isso, peca pelo excesso ou pelo apagamento dos traços. Transita em dois extremos, assim como o castelo de vidro e o espaço de pelúcia, citado por Benjamin.

O rastro está no equívoco, no esquecimento, no que está para sempre perdido, talvez como uma única via possível de reinvenção. Ele convoca à manutenção do mistério, vulnerabilidade necessária para aproximação com a humanidade que nos habita.

Nesse sentido Gagnebin é categórica:

enquanto os signos, sobretudo os signos linguísticos, tentam transmitir uma mensagem relacionada às intenções, às convicções, aos desejos do seu autor, o rastro pode se voltar contra aquele que o deixou e até ameaçar sua segurança. (GAGNEBIN, 2014, pg, 115).

Voltando à exposição e à pergunta lançada no início: como se opera a transmissão se carentes estamos de uma palavra comum que nos constitua e nos conecte? O quê da memória de um estranho me convoca e me remete à uma memória inexistente em mim, de um lustre que nunca vi, um corredor que não pisei, do piano de cauda que jamais tocarei e da compoteira usada para guardar as contas a pagar que não são as minhas?

Parece que a possibilidade de transmissão se dá nas bordas do ser, no que Jean-Luc Nancy, em a Comunidade Inoperante (2006), trata como uma existência fora de nós mesmos, de seres que se convocam e se reconhecem nos limites de sua finitude. Onde não mais sou, ou no limite do eu, me encontro com o outro. Esse espaço vazio que evidencia o rastro e onde, através de alguma invenção, conecto-me ao outro. Uma abertura para a palavra comum. Assim como é na poesia, escrita enigmática, que opera na borda da letra e denuncia a presença de um ausente.

\section{Antes de Sair}

De algum modo, esse apartamento possuía vestígios de alguém que o habitou, "um ambiente imutável que exalava a segurança da previsibilidade", como escreve o artista em um dos textos expostos. Um lugar de coisas pequenas e coisas no limbo, que em dias de faxina reapareciam e retomavam os seus lugares habituais.

A sua desocupação permitiu que alguém recolhesse os rastros deixados na normalidade dos excessos, para não mostrá-los nas imagens, e conduzi-los através de um texto poético. Imagens e escrita, que deixam para trás restos não intencionais, apontando uma via possível para a demolição de castelos de vidro, ou a varredura dos espaços de pelúcia, permitindo, assim, vero seu interior, e não somente ao que está dentro.

O que está dentro talvez esteja aprisionado. Mas o que está no interior avança para fora, carregando rastros em público, para ganhar outros 
Imagem da obra "As coisas pequenas", Exposição Antes de Sair, artista Luiz Ernesto, Paço Imperial, Rio de Janeiro, 2017.
Imagem da obra "Antes de sair", Exposição Antes de Sair, artista Luiz Ernesto, Paço Imperial, Rio de Janeiro, 2017.
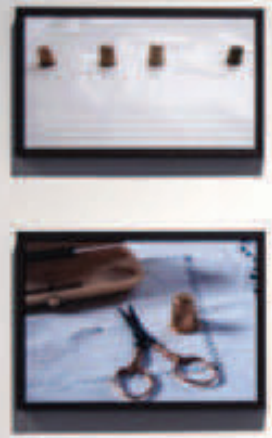

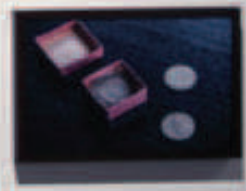

“interiores". Traços como enigmas, que não se sabe ao certo o que são, ou o que poderiam ser, senão sob a condição vulnerável de invenção a partir de um tempo presente. Na desmecanização das palavras, a transmissão possui espaço suficiente de manobra para seguir seu curso. É preciso não saber, para transmitir.
Antes de sair, as palavras que criaram a última imagem, da casa que não mais existe:

Sem os móveis e os objetos, os percursos se apagaram. Caminhar pelos ambientes do apartamento, agora vazio, era andar à deriva, sem as marcações da coreografia imposta pela presença das coisas. Sua identidade agonizava,
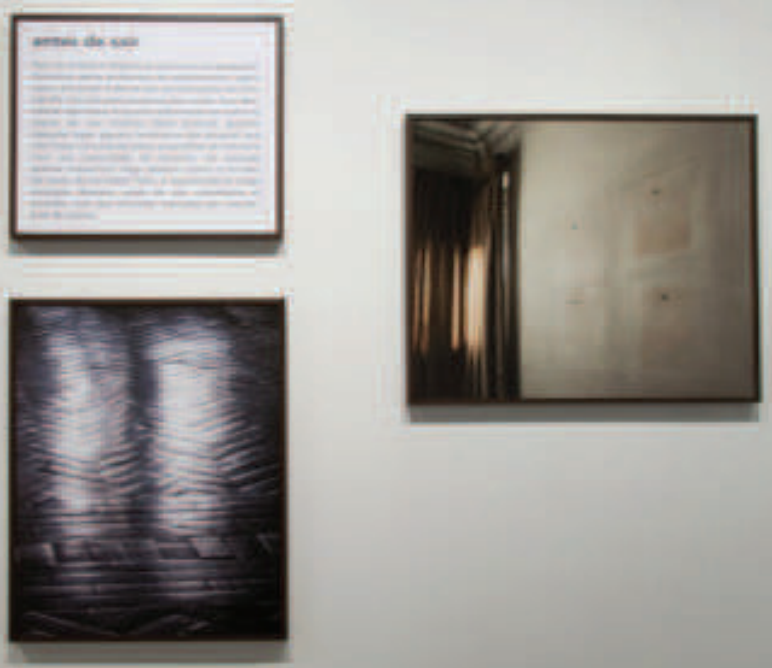
enquanto esfumavam-se todos os traços de sua história. Seria possível guardar daquele lugar, alguma lembrança tão tangível que não fosse corrompida pelas armadilhas da memória com sua capacidade de decantar do passado apenas resquícios? Algo objetivo como o número de tacos do corredor? Não, o esquecimento exige rendição. Restava, antes de sair, contemplar as paredes nuas dos cômodos marcadas por monotipias de poeira. (LUIZ ERNESTO, 2017)

\section{Referências}

BENJAMIN, Walter. Magia e técnica, arte e política: ensaios sobre literatura história da cultura (Obras escolhidas, v.1); tradução Sérgio Paulo

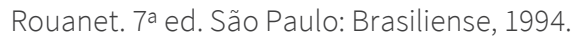

FLUSSER, Vilém. Prétextos para a poesia in Caderno Rioarte, ano 1, n³, 1985, p.18.

GAGNEBIN, Jean Marie. Lembrar, escrever, esquecer. "O rastro e a cicatriz: metáforas da memória." 2a ed. São Paulo: Editora 34, 2014.

NANCY, Jean-Luc. La comunidad inoperante. Trad. João Manuel Garrido Wainer. Santiago de Chile: Escuela de Filosofía Universidad ARCIS, 2000.

RAMOS, F.R.L. Cultura material e escrita da história: a imposição da palavra na exposição do objeto. In: SaragFassaBenechetirt; Rafael Zamorano Bezzera, Aline Montenegro Magalhães. (Org.). Museus e Comunicação: exposição como objeto de estudo. $1^{a}$ ed. Rio de Janeiro: Edições do Museu Histórico Nacional, 2010, v. 1, p. 155-175.

\section{Referências em meio Eletrônico}

Site Canal Arte (www.canal-arte.com), entrevista concedida pelo artista Luiz Ernesto em 07 de Abril de 2017. Acesso no endereço https:// www.youtube.com/watch?v=DI3rsOKOutl, em 10 de Agosto de 2018. 